\title{
Estudo de caso de três espécies de plantas bioindicadoras de solos salinos
}

\section{Case study of three species of saline soil bioindicators}

\author{
Mercia F. Carvalho ${ }^{1}$; Soraya G. El-Deir ${ }^{2}$; Marcus M. Corrêa ${ }^{3}$; Gian C. Carvalho ${ }^{4}$
}

Resumo: Bioindicadores, de uma maneira geral, são seres vivos de natureza diversa, vegetais ou animais, utilizados para analisar a qualidade de um determinado ambiente. A degradação ambiental do solo pela salinidade é um problema muito antigo e de extensão mundial, geralmente, mais pronunciado nas regiões áridas e semi-áridas. As plantas que se desenvolvem em áreas com elevadas concentrações de sais são chamadas de halófitas, e algumas delas são usadas na recuperar desses solos. O objetivo desse trabalho é analisar três espécies de plantas resistentes ao estresse salino gerar recomendações a respeito das mesmas, disponibilizando uma indicação de espécie que possa recuperar o ambiente salinizado. Foram selecionadas aleatoriamente três espécies de plantas resistentes a salinidade Copernicia prunifera, Atriplex nummularia L. e Gossypium hirsutum L, as mesmas foram analisados por uma planilha com características que identificam um bioindicador ideal e em seguida as espécies foram avaliadas de acordo com sua fisiologia e etiologia. Embora as propriedades da espécie A. nummularia tenha se destacado por recuperar os solos salinizados a espécie Copernicia prunifera foi considerada como um bioindicador ideal. Recomendam-se ainda estudos mais aprofundados acerca desse assunto.

Palavra chave: halófitas, atriplex nummularia, copernicia prunifera, gossypium hirsutum

Abstract: Bioindicators, in general, living organisms are diverse in nature, plant or animal used to assess the quality of a given environment. Environmental degradation by soil salinity is a very old problem and expanse world generally more pronounced in arid and semi-arid regions. Plants that thrive in areas with high concentrations of salts are called halophytes, and some of them are used in recovering these soils. The aim of this work is to analyze three species of plants resistant to salt stress generate recommendations regarding the same, providing an indication of species that can restore the environment salinized. Randomly selected three species of plants resistant to salinity Copernicia prunifera, Atriplex nummularia L. and Gossypium hirsutum L, they were analyzed by a spreadsheet with characteristics that identify an ideal bioindicator species were then evaluated according to their physiology and etiology. Although the properties of A. nummularia has been highlighted by the recovery of soil salinized species Copernicia prunifera was considered as an ideal biomarker. Recommend to still further studies on this subject.

Key words: halophytes, atriplex nummularia, copernicia prunifera, gossypium hirsutum

\footnotetext{
*Autor para correspondência

Recebido para publicação em 14/08/2014; aprovado em 10/07/2015

${ }^{1}$ Farmacêutica. Mestranda em Engenharia Ambiental da Universidade Federal Rural de Pernambuco - UFRPE. E-mail: mercia.fonseca@ gmail.com

${ }^{2}$ Biologa, Doutora em Oceanografia, Professora da Universidade Federal Rural de Pernambuco - UFRPE, Recife, PE, sorayageldeir@ gmail.com.

${ }^{3}$ Agrônomo, Doutor em Engenharia Agrícola, Professor da Universidade Federal Rural de Pernambuco - UFRPE, Recife, PE, mmetri@ig.com.br.

${ }^{4}$ Eng. Agr. Doutorando em Engenharia Agrícola da Universidade Federal Rural de Pernambuco - UFRPE. E-mail: giancarvalho@gmail.com.
} 


\section{INTRODUÇÃO}

Os bioindicadores são conjuntos de espécies ou comunidades biológicas cuja presença, diversidade e condições são indicativos biológicos de uma determinada situação ambiental, relevantes para correlacionar com um determinado fator antrópico e/ou natural que cause impacto, sendo importante para verificar a integridade ecológica, auxiliando na identificação de áreas degradadas e na recuperando das mesmas.

A presença de elevadas concentrações de sais solúveis no solo é caracterizado como solo salino. Esses solos são comumente encontrados em áreas de climas áridos e semiáridos. No nordeste a irrigação mal manejada tem causado a salinização de muitas áreas, trazendo problemas ambientais como a contaminação de lençóis freáticos podendo afetar à água potável e o equilíbrio dos ecossistemas.

Plantas são organismos sésseis e, portanto, refletem as condições locais. Elas apresentam geralmente maiores níveis de plasticidade fenotípica comparado aos animais, o que significa que efeitos de diversos estressores podem ser mais aparentes e, potencialmente, mais fáceis de serem medidos e quantificados. Do ponto de vista fisiológico, o que leva as plantas a uma desestabilização das funções normais é o estresse, podendo ser caracterizado como um estado em que ocorrem demandas crescentes de energia pela planta. Como as plantas são suscetíveis a uma diversidade de estresses elas tendem a reduzir suas chances de sobrevivência e desenvolvimento.

As halófitas são plantas que crescem em locais com altas concentrações de sal ao contrario das glicófitas representada pela maioria das espécies de plantas, sofrem por causa das elevadas concentrações de sais no solo, o aumento do efeito osmótico na solução aquosa prejudica a absorção de água pelas raízes ocasionando deficiência hídrica nas plantas e danos nas folhas, além da diminuição da produtividade do vegetal, modificando o seu crescimento e causando alterações na fotossíntese.

Algumas plantas conseguem se adaptar aos solos salinos outras podem ser utilizadas na recuperação desses solos retirando o sal dos mesmos. Essas plantas são tolerantes à salinidade encontradas geralmente em ambientes de clima seco e adaptadas ao semiárido nordestino, podem ser usadas como bioindicadores de salinidade. Desta forma, espera-se com o presente estudo analisar três espécies de plantas resistentes ao estresse salino gerar recomendações a respeito das mesmas, disponibilizando uma indicação de espécie que possa recuperar $\mathrm{o}$ ambiente salinizado.

\section{IDENTIFICAÇÃO DE BIOINDICADORES}

As espécies, grupos de espécies ou comunidades biológicas que estão adaptadas para sobreviver, se reproduzir e realizar relações ecológicas em condições ambientais específicas cuja presença, abundancia e condições de vida denotam indicativos biológicos de uma determinada condição ambiental são chamados de bioindicadores (EL- DEIR \& LEITÃO, 2009). Desta forma, a presença de cada tipo de ser vivo indica características físicas, químicas e estruturais do ambiente em que se encontra.

Os bioindicadores são importantes para: fornecer sinais rápidos sobre problemas ambientais, mesmo antes do homem saber sua ocorrência e amplitude; permite identificar as causas e os efeitos entre os agentes estressores e as respostas biológicas; oferecer um panorama da resposta integrada dos organismos e modificações ambientais e permite avaliar a efetividade de ações mitigadoras tomadas para contornar os problemas criados pelo homem.

O bioindicador ideal é caracterizado por ser: espécie taxonomicamente bem definida, facilmente reconhecida por não especialistas, apresentar distribuição geográfica ampla, ser abundante, ter baixa variabilidade genética e ecológica, ter preferencialmente um tamanho grande e longo ciclo de vida, dispor de características ecológicas bem definidas e conhecidas e ter possibilidade de uso em estudos em laboratório (Johnson et al., 1993).

Certas espécies respondem a alterações ambientais com o surgimento de poluentes, desaparecimento ou se multiplicando. Para analisar essas alterações precisa-se de conhecimento profundo da fisiologia, etiologia da espécie, dinâmica da população e relação com as demais populações da comunidade.

O biomonitoramento é usado para monitorar as alterações ambientais, através da quantidade de parâmetros nos organismos vivos. Observação continua, no espaço e no tempo dos bioindicadores. A bioindicação por sua vez é o estudo da alteração da diversidade das espécies face a uma alteração ambiental, consiste no uso de organismos para obter informações sobre a qualidade do ambiente terrestre ou aquático num determinado instante.

De acordo com El-Deir \& Leitão, 2009 para identificar essas espécies como bioindicador é preciso classifica-las como:

Os organismos são classificados, entre outros, como indicadores acumulativos, indicadores de respostas, organismos indicadores, organismos teste e organismos monitores, sendo que os monitores podem ser passivos e ativos. Tipos de monitores: os organismos podem ser monitores das condições ambientais, ou seja, no monitoramento qualitativo e quantitativo do nível de poluentes no meio ambiente e sua repercussão na ecologia. São identificados como monitor passivo os presentes no ecossistema fazendo parte da biota (faz parte da biodiversidade alfa) e monitor ativo os que foram introduzidos no ecossistema (faz parte da biodiversidade beta e ou gama).

Com relação a tolerância fisiológica e etiológica que está relacionada de acordo com o nível de tolerância que o individuo, espécie, população ou comunidade apresenta face a uma dada alteração ambiental. Pode ser classificado como péssimo fisiológico se o fator ocorre em intensidade baixa ou elevada demais, porém em nível suportável ou ótimo fisiológico se o fator alcança intensidade especificamente favorável. Quanto à amplitude do nível de tolerância conceitua-se os euripotentes organismos que suportam elevada variação (amplitude) de um fator e os estenopotentes como aqueles que apresentam estreita variação (amplitude) de um fator.

$\mathrm{Na}$ natureza, por regra, a bioindicação se registra em 
cadeias de reações ou processos. Se o fator antrópico atua diretamente sobre o sistema biológico, fala-se em bioindicação direto (primário). Em muitas situações a bioindicação se manifesta como resultado de alterações de condições ambientais, que provocam respostas diferentes. Temos então a bioindicação indireto (secundário).

De acordo com a sucessão ecológica, ou seja, como as espécies vão surgindo em determinados ambientes, as que apresentam condições para povoarem espaços em substituição as espécies originais são denominadas de oportunistas, generalistas, R-estrategista e as que possui uma maior exigência ambiental, são especializadas a respeito de um fator, não suportando sua variação denomina-se como especialistas ou Kestrategista.

Relacionado a tipologia dos bioindicadores os de curto tempo estão vinculado aos indivíduos, com alteração no seu comportamento e fisiologia, acontece o estimulo e a resposta é imediata os de longo tempo vinculado a estrutura da comunidade ou densidade da população, a resposta é mediata o estimulo acontece e existe uma acumulação e a resposta vai sendo gradativa.

Com frequência, o conceito bioindicação é usado para definir reações, dependentes de uma variável temporal, a um fator ambiental antrópico ou modificado antropicamente, manifestadas através de respostas mensuráveis provenientes de um objeto ou sistema biológico. Essas respostas têm que ser comparáveis em situações padronizadas. No que se refere à escala cronológica de reação, os bioindicadores se classificam em seis diferentes tipos: I) após um determinado período, no qual ele não mostra nenhuma reação (no effect level); II) bioindicador reage com uma única forte resposta voltando a não mostrar nenhuma reação mais (upper effect level); III) como no caso anterior, a resposta ocorre repentina e intensamente, permanecendo por algum tempo, desaparecendo rapidamente; IV) bioindicador reage desde o início do fator estressor com intensidade contínua durante muito tempo; V) após uma forte reação imediata, esta apresenta-se cada vez mais fraca; VI) reação imediata com o início do estresse, se intensificando continuamente até alcançar o máximo, reduzindo sua intensidade progressivamente e os de ciclos alternados de respostas fortes e fracas, sucessivamente.

Com relação a especialidade do fator a ser identificado com o uso do bioindicador: os não especialistas que sofre a alteração, a reação pode ser provocada por diferentes fatores ambientais e os específicos quando a reação é especifica para fatores de reação ambiental. Relacionado ao tipo de reação pode ser sensível reage com as alterações etiológicas e os acumulativos que não tem reação.

De acordo com a estrutura morfológica e a bioindicação podemos classificar como: Clorose quando ocorre perda da cor, a descoloração de folhas é considerada como reação não especifica a diferenças estressoras.

Coloração amarelada nas bordas (emersões contendo $\mathrm{Cl}$ ); Coloração avermelhada (emissões ricas em $\mathrm{SO}_{2}$ ); Coloração amarronzada ou bronzeada (necrose); Coloração prateada (presença de $\mathrm{O}_{3}$ ).

Necrose intercostal, quando ocorre morte do tecido entre nervuras (presença de $\mathrm{SO}_{2}$ ); Necrose lateral, bem características nas bordas das folhas; Necrose acicular frequentes em pinheiros; Necrose marrom escura nas extremidades; Necrose em frutos o estresse é provocado pela presença de $\left(\mathrm{SO}_{2}\right)$.

Queda foliar geralmente ocorre após o aparecimento de necrose ou clorose.

Alterações em órgãos, forma anormal de folhas, galhos tortos, tamanho pequeno, alterações dos órgãos reprodutivos, mudança de sexo ou outras anormalidades.

\section{CARACTERÍSTICAS DE PLANTAS DE SOLOS SALINOS}

A salinização do solo influencia diretamente no metabolismo das plantas, impedindo a absorção de água e outros nutrientes, somado ao fato de que certos íons constituintes dos sais, quando adsorvidos em altas quantidades, provocando modificações no balanço nutricional capaz de resultar em clorose e necrose nas folhas, reduzindo a produção e, às vezes, morte da planta jovem (JINDAL et al., 1976).

Os efeitos de grandes concentrações de sais solúveis se manifestam através da elevada pressão osmótica e à ação tóxica de alguns elementos como o $\mathrm{Na}^{+}$e o $\mathrm{Cl}^{-}$, que causam distúrbios fisiológicos à planta, podendo provocar a morte (MELO et al., 1983). Segundo Taiz e Zeiger (2004), dependendo do comportamento das plantas ao serem submetidas a condições salinas podem ser classificadas, em halófitas e glicófitas.

As halófitas possuem propriedades fisiológicas e anatômicas capazes de apresentar tolerância ao sal devido à sua capacidade de compartimentalização dos íons no vacúolo da célula. A resistência dessas plantas a salinidade se deve à capacidade de evitar que elevadas concentrações de sal, resultante do substrato, alcancem o protoplasma e, por meio de regulação salina, de tolerar os efeitos tóxicos e osmóticos associados ao aumento na quantidade de sais (LARCHER, 2000). As glicófitas por sua vez, quando submetidas a altas concentrações de sais indicam sinais de inibição do crescimento, descoloração foliar e perda de peso seco, sendo sintoma mais característico a inibição do crescimento (MUNNS, 2002).

As halófitas, devido a suas elevadas taxas de acumulação e absorção de sais nos tecidos, sobretudo na parte aérea, possuem habilidade de remover sais do solo. A fitorremediação é uma eficiente técnica de recuperação de solos salinos e sódicos tanto pela remoção consideráveis de sais quanto pela melhoria da estruturação do solo e incremento da atividade biológica quando as plantas são introduzidas em áreas sem cobertura vegetal (FREIRE, et al., 2010).

\section{ESTUDO DE CASO}

\section{Características da sistemática das espécies}

Um dos maiores grupos de seres vivos com cerca de 400.000 espécies conhecidas é o reino Plantae, nele estão presentes as ervas, árvores, arbustos, plantas etc. É constituído por seres pluricelulares e eucariontes, que são autotróficos produzem o próprio alimento pelo processo da fotossíntese (BARROSO et al., 1978a).

As Magnoliophyta ou angiospermas é o maior grupo de plantas atualmente vivente, ocorrendo praticamente em todos 
os biótopos do planeta, predominando na maioria das comunidades vegetais, são plantas que produzem sementes encerradas no ovário e, portanto, podem formar frutos (BARROSO et al., 1991b).

Liliopsida é uma classe constituída por cerca de 50.000 espécies de angiospermas, as vezes é referida como monocotiledôneas, compreendendo plantas com sementes que produzem um embrião com um único cotilédone e folhas paralelo: inclui gramíneas, lírios, palmeiras e orquídeas (TAKHTAJAN, 1980).

As Magnoliopsida ou dicotiledôneas é uma classe pertencente à divisão Magnoliophyta, possuem cerca de $170 \mathrm{mil}$ espécies de angiospermas. Seu embrião (semente) contém dois ou mais cotilédones, possuem raiz axial e folhas com nervação reticulada. As partes florais podem ser pentâmeras (mais frequente), as vezes tetrâmeras, raramente, monômeras (BARROSO et al., 1991a).

A única da ordem Arecales é a Palmeira nome comum das plantas da família Arecaceae, pertencem a esta família plantas muito conhecidas, como o coqueiro e a tamareira, abrangendo aproximadamente 205 gêneros e 2.500 espécies. Distribuem-se pelo mundo todo, mas estão centralizadas nas regiões tropicais e subtropicais. São plantas perenes, arborescentes, tipicamente com um caule cilíndrico não ramificado do tipo estipe, atingindo grandes alturas, mas por vezes se apresentando como acaule (caule subterrâneo). Não são consideradas árvores porque todas as árvores possuem o crescimento do diâmetro do seu caule para a formação do tronco, que produz a madeira e tal não acontece com as palmeiras (D'ELBOUX, 2006).

Caryophyllales é uma ordem que apresenta evidências de uma derivação da Renunculales. A maioria dos integrantes dessa ordem apresenta pigmento betalina em vez de antocianinas, possui um cálice petalóide, brácteas que apresentam um estágio intermediário de um pseudocálice (BARROSO et al., 1978a).

A ordem Malvales tem seis famílias e cerca de 3.500 espécies distribuídas nas regiões tropicais e subtropicais e temperadas do globo. São plantas lenhosas, com folhas simples ou compostas, alternas estipuladas, via de regra, com indumento de pelos ramificados. Flores andróginas ou unissexuadas, pentâmeras, com cálice de sépalas valvares e corola com pétalas imbricadas ou torcidas (BARROSO et al., 1978a).

Amaranthaceae família formada por cerca de 60 gêneros e 900 espécies é difundida nos trópicos, subtrópicos e regiões temperadas da América e África. No Brasil, ocorrem 12 gêneros com cerca de 86 espécies, sua subfamília é Chenopodioideae. São ervas anuais ou perenes, raramente subarbustos, com folhas alternada ou pequena, disposta em inflorescências densas, capituliformes, ou em espigas congestas ou em panículas laxas (BARROSO et al., 1978a).

As Malvaceae é uma família que tem no Brasil cerca de 31 gêneros e 200 espécies. São subarbustos ou arbustos, raramente árvores de pequeno porte, com canais mucilaginosos e indumento constituído, frequentemente de pêlos ramificados ou escamosos (BARROSO et al., 1978a).
Sistemática da Copernicia prunifera

Reino: Plantae

Divisão: Magnoliophyta

Classe: Liliopsida

Ordem: Arecales

Família: Arecaceae

Gênero: Copernicia

Espécie: C. prunifera, (Miller) H.E. Moore, 1963

\section{Dados ecológicos}

A Copernicia prunifera, é uma palmeira nativa do nordeste brasileiro com ocorrência predominantemente nos estados do Piauí, Ceará e Rio Grande do Norte. É uma planta de grande aproveitamento, suas as folhas, fornece o pó, que é a principal matéria-prima da cera de carnaúba, utilizadas na cobertura de casas e para confecção de peças de artesanato, seus frutos servem para alimentação animal, o talo é usado na construção civil, sua raiz tem propriedade medicinais e a cera tornou-se o produto de maior valor da palmeira utilizada como matéria-prima em setores de grande destaque mundial, como é o caso da indústria de informática (CARVALHO; GOMES, 2005).

Copernicia prunifera ocorre com frequência em terrenos salinizados e mal drenados, crescem ao longo de rios, vales e lagoas do nordeste brasileiro (ARRUDA; CALBO, 2004). A espécie Copernicia prunifera é caracterizada como plantas halófitas em virtude da ocorrência natural em solo salinos, consequentemente, possa ser utilizada como uma das espécies para a revegetação de áreas com solos salinizados no semiárido brasileiro (HOLANDA; ARAÚJO et al., 2011). É uma planta de grande longevidade, supõe-se que viva até 200 anos, capaz de viver por longas estações secas. Gomes (1946), em seu experimento verifica que a primeira folha da plântula surge com 40 dias de semeadura e sua raiz atinge $15 \mathrm{~cm}$ de profundidade, esse crescimento acelerado das raízes explica a resistência desta espécie às estiagens, e a continuidade de seu crescimento mesmo ao longo de vários meses de seca completa.

A degradação ambiental do solo pela salinidade é um problema muito antigo e de extensão mundial, sendo, geralmente, mais pronunciado nas regiões áridas e semi-áridas (TOPPA; BRAMBILLA, 2011). A espécie Copernicia prunifera por serem encontradas em áreas salinas pode ser caracterizada como bioindicador de solos salinos.

De acordo com o trabalho desenvolvido por Holanda et al. (2011), embora a carnaúba seja encontrada em solos halomórficos, o limite de tolerância à salinidade encontrado neste estudo é inferior ao já registrado em espécies de dicotiledôneas. A Copernicia prunifera por tolerar apenas níveis intermediários de salinidades, pode ser classificada como glicófita.

Holanda (2006) relata que a salinidade prejudicou cada variável avaliada de forma desigual: altura, largura, massa fresca e seca da parte aérea e massa fresca e seca das raízes, sendo mais crítico na produção de matéria seca da raiz. Em concentrações maior ou igual a $100 \mathrm{~mol}^{-3}$ de $\mathrm{NaCl}$ o desenvolvimento e possivelmente a vida da planta foi comprometida. 
Sistemática da Atriplex nummularia L.

Reino: Plantae

Divisão: Magnoliophyta

Classe: Magnoliopsida

Ordem: Caryophyllales

Família: Amaranthaceae

Subfamília: Chenopodioideae

Gênero: Atriplex

Espécie: A. nummularia L. (Lindl.)

Dados ecológicos

Atriplex nummularia L. conhecida como erva sal, originária do interior australiano, é uma planta forrageira arbustiva exótica, de vida longa, vivem em ambientes áridos e semi-áridos de diversos continentes, se desenvolve bem em solos com alto teor de sal. O gênero Atriplex conta com cerca de 400 espécies distribuídas nas diversas regiões áridas e semiáridas do mundo, das quais umas 50 apresentam valor forrageiro, conhecido por apresentar forte resistência a ambientes secos e salinizados, conhecida pela capacidade de acumular grandes quantidades de sais em seus tecidos (HERRERA et al., 2000). Segundo Bonilla et al. (2000), os sais extraídos pelas Atriplex são necessários para seu metabolismo. Em estudo realizado por Leal et al. (2008), Atriplex nummularia comportou-se como planta hiperacumuladora de sódio, com potencial de uso na fitoextração deste elemento no solo. Por este gênero tolerar tais habitats tornam-se uma alternativa para recuperar ambientes degradados pela salinidade.

De acordo com Porto et al. (2006), dentre as halófitas, a Atriplex nummularia é uma das mais importantes, pelo fato de possuir mecanismos especializados de acumulação de sais no seu interior e de sua eliminação através das folhas, essa a planta se comporta desta maneira não por serem especializadas na absorção de sais mas, como forma sobrevivência ao ambiente quando este é de elevada salinidade.

Trabalhos realizados em laboratório com espécies Atriplex halimus, demonstraram que esta planta pode crescer muito bem quando irrigadas com solução salina contendo $30.000 \mathrm{mg} / \mathrm{litro}$ de cloreto de sódio, (ZID, 1970).

Sistemática do Gossypium hirsutum L.

Reino: Plantae

Divisão: Magnoliophyta

Classe: Magnoliopsida

Ordem: Malvales

Família: Malvaceae

Gênero: Gossypium

Espécie: G.hirsutum L. (Cronquist, A. 1981)

Dados ecológicos

Comumente conhecido como algodão o Gossypium hirsutum é nativo da America Central e possivelmente do México, seu gênero compreende 50 espécies. É um arbusto perene, geralmente crescem no habitat de caatinga, cerrado e mata atlântica e possui um ciclo de vida curto (OVERSTREET, 1999). Segundo Berg (2005), Gossypium hirsutum é um arbusto com até $3 \mathrm{~m}$ de altura, suas folhas alternas, simples, com estípulas; pecíolo glabro; limbo digitado com 3 lobos, membranáceo, glabro, de coloração verde-escura na face ventral e verde-clara na face dorsal, presença de pontuações de cor vinho no pecíolo e no limbo, flores axilares, o fruto é uma cápsula verde, contendo sementes envolvidas em algodão branco.

Nas regiões áridas e semi-áridas do mundo, o excesso de sais no solo tem limitado a produção agrícola, principalmente em áreas irrigadas. Por causa do elevado teor de sais nos solos são testadas espécies de Gossypium hirsutum L. tolerantes a essas condições (PRIMO JUNIOR et al., 2005). Apesar de ser considerada resistente a salinidade a cultura do algodão quando exposto a essas condições pode sofrer reduções substanciais no crescimento e em sua produção (PRIMO JUNIOR et al., 2005). Em estudo desenvolvido por Queiroz e Bull (2001) verificaram que com o aumento na concentração de sódio na solução de solo, prejudicou o crescimento das plantas, a produção de matéria seca e a área foliar não havendo alteração expressiva no teor de clorofila, nas cultivares de algodão avaliado. Os níveis de salinidade do solo a partir de $16 \mathrm{dS} . \mathrm{m}^{-1}$ afetaram negativamente o crescimento das plantas.

O algodoeiro é considerado uma cultura moderadamente tolerante a presença de sais no solo (TAIZ \& ZEIGER, 2004), contudo, diversos trabalhos demonstram a sensibilidade de cultivares de algodoeiro ao estresse salino.

\section{METODOLOGIA}

Com o intuito de contemplar a problemática levantada, optou-se por uma pesquisa de natureza exploratória e descritiva de abordagem quali-quantitativa, pois permitirá uma maior aproximação e entendimento da pesquisa com o seu objeto de estudo. Esse tipo de pesquisa exploratória e descritiva consiste em proporcionar maior familiaridade com o problema, aprimoramento de ideias e descoberta de intuições e a descrição das características de determinada população ou fenômeno, respectivamente, o que foi de extrema importância para a realização da pesquisa essa fundamentação e descrição. Dessa forma foi feito um levantamento de dados secundários em livros, artigos, internet, dissertações e teses.

Foram selecionadas três espécies Copernicia prunifera, Atriplex nummularia L. e Gossypium hirsutum L. essas se desenvolvem em solos salinos a escolha das mesmas foi realizada de forma aleatória.

Para melhor identificação dos preceitos analíticos, as espécies foram tipificadas em sp1 Copernicia prunifera, sp2 Atriplex nummularia L. e sp3 Gossypium hirsutum L. Usou-se para analise quali-quantitativa uma planilha com informações necessárias para atingir os objetivos propostos. Nessa planilha foi descrito 10 características que identifica bioindicadores ideais cada característica tem um peso 1 a 3 e cada espécie recebeu valores de 1 a 5 sendo $1=$ característica pouco marcante e $5=$ característica muito marcante essa qualificação foi de extrema importância na identificação das espécies que são boas bioindicadores de solos salinizados. Uma analise comparativa também foi realizada com as espécies de acordo com sua fisiologia e etiológica. 


\section{RESULTADOS E DISCUSSÃO}

Por meio dos dados apresentados na Tabela 1, verificase que todas as espécies avaliadas obtiveram pontuação total acima de 50 sendo a de maior destaque a Gossypium hirsutum com média de 8,4 e mediana 8 caracterizando-se por apresentar os valores mais elevados nos quesitos taxonomicamente bem definida, distribuição geográfica ampla e ser abundante demonstrando-se uma espécie potencialmente bioindicadora. Segundo BRASIL (2006) as espécies do gênero Gossypium possui uma grande distribuição geográfica e a espécie $G$. hirsutum é a mais abundante no Brasil por ser um dos maiores produtores de algodão.
As três espécies analisadas possuem tamanho grande e baixa mobilidade além de possibilidade de uso em estudos em laboratório (Tabela 1). O reino plantae é caracterizado por seres que não podem se locomover. Para conseguir seu alimento as espécies desse reino através da fotossíntese, produzem matéria orgânica que é utilizada como alimento (BARROSO et al., 1991b). De acordo com Rocha et al., 2011; Berg, 2005 e Porto et al., 2006 as espécies avaliadas possuem tamanho acima de $1 \mathrm{~m}$ de altura a espécie $C$. prunifera é uma palmeira de tronco único, adulto pode atingir altura superior a 10 metros, a $G$. hirsutum é arbusto com até $3 \mathrm{~m}$ de altura e a A. nummularia possui altura média com um ano de idade de $2,20 \mathrm{~m}$.

Tabela 1. Características ideais dos bioindicadores

\begin{tabular}{|c|c|c|c|c|c|c|c|}
\hline \multirow{2}{*}{ CARACTERÍSTICA } & \multirow{2}{*}{$\frac{\text { ESPÉCIES }}{\text { P }}$} & \multirow[b]{2}{*}{ Sp1 } & \multirow[b]{2}{*}{ PT } & \multirow[b]{2}{*}{ Sp2 } & \multirow[b]{2}{*}{ PT } & \multirow[b]{2}{*}{ Sp3 } & \multirow[b]{2}{*}{ PT } \\
\hline & & & & & & & \\
\hline $\begin{array}{l}\text { Taxonomicamente bem definida } \\
\text { (espécie). }\end{array}$ & 3 & 4 & 12 & 4 & 12 & 5 & 15 \\
\hline $\begin{array}{l}\text { Facilmente bem reconhecida por não } \\
\text { especialista. }\end{array}$ & 1 & 4 & 4 & 2 & 2 & 4 & 4 \\
\hline Distribuição geográfica ampla & 2 & 2 & 4 & 2 & 4 & 4 & 8 \\
\hline Ser abundante. & 2 & 1 & 2 & 2 & 2 & 4 & 8 \\
\hline $\begin{array}{l}\text { Baixa variabilidade genética e } \\
\text { ecológica. }\end{array}$ & 2 & 3 & 6 & 2 & 4 & 3 & 6 \\
\hline Tamanho grande. & 1 & 5 & 5 & 5 & 5 & 5 & 5 \\
\hline Baixa mobilidade. & 2 & 5 & 10 & 5 & 10 & 5 & 10 \\
\hline Ciclo de vida longo. & 2 & 5 & 10 & 5 & 10 & 3 & 6 \\
\hline $\begin{array}{l}\text { Características ecológicas bem definidas } \\
\text { e conhecidas. }\end{array}$ & 3 & 4 & 12 & 3 & 9 & 4 & 12 \\
\hline $\begin{array}{l}\text { Possibilidade de uso em estudos em } \\
\text { laboratório. }\end{array}$ & 2 & 5 & 10 & 5 & 10 & 5 & 10 \\
\hline Total & & & 75 & & 68 & & 84 \\
\hline Média & & & 7,5 & & 6,8 & & 8,4 \\
\hline Mediana & & & 8 & & 7 & & 8 \\
\hline
\end{tabular}

Sp1 = C. prunifera $; \mathbf{S p ~ 2 = ~ A . ~ n u m m u l a r i a ~} ; \mathbf{S p 3 = ~ G . ~ h i r s u t u m ; ~} \mathrm{P}=$ Peso (características); $\mathrm{P} . \mathrm{T}=$ Pontuação Total.

Classificação das espécies de acordo com sua fisiologia e etiológica

\section{a) Copernicia prunifera}

A classificação fisiológica e etiológica da Copernicia prunifera pode ser analisada como sendo um monitor passivo, pois é encontrada no ecossistema ocorrendo com frequência em terrenos salinizados habitando ao longo de rios, vales e lagoas. (ARRUDA; CALBO, 2004). É um péssimo fisiológico e estenopotente por possuir níveis de tolerância a salinidade do solo segundo trabalho desenvolvido por Holanda et al. (2011), embora a Copernicia prunifera seja encontrada em solos halomórficos, o limite de tolerância à salinidade encontrado é inferior ao já registrado em espécies de dicotiledôneas, essa planta tolera níveis intermediários de salinidades. Bioindicador direto (primário) o desenvolvimento e possivelmente a vida da planta foi comprometida em concentrações maior ou igual a 100 mol. $\mathrm{m}^{-3}$ de $\mathrm{NaCl}$ (HOLANDA, 2006).

Pelos fatores mencionados nota-se que a Copernicia prunifera possui uma experiência em solos salinos, se modificando conforme a variação por estes motivos pode-se considera como sendo K-estrategista. De longo tempo o estimulo acontece e se acumula dando uma resposta gradativa, quanto a questão temporal a Copernicia prunifera reagem com intensidade durante muito tempo. São acumuladoras acumulam substancias, podendo refletir uma memória ambiental temporal. De reação não especifica sofrendo alteração conforme provocada por diferentes fatores ambientais. Sensível por reagir a alterações etiológicas.

\section{b) Atriplex nummularia L.}

Por crescerem e se adaptarem bem em solos degradados por sais é considerada como monitor passivo, presentes no ecossistema conhecida pela capacidade de acumular grandes quantidades de sais em seus tecidos (HERRERA et al., 2000). Possui um ótimo fisiológico e são euripotentes por serem capazes de extrair o sal do solo recuperando a área degradada (PORTO et al., 2006). Bioindicador direto (primário) vários autores relatam que a Atriplex nummularia L. é muito resistente ao estresse salino e necessita desse sais para o seu metabolismo (ZID, 1970; HERRERA et al., 2000; BONILLA et al., 2000; PORTO et al., 
2006 \& LEAL et al., 2008).

Pode ser considerada como R- estrategista espécies oportunistas que aproveitam condições para povoarem espaços em substituição espécies originais. Não tem resposta o estimulo e não é suficiente para que haja resposta. $\mathrm{Na}$ analise temporal elas essas plantas se comportam como bioacumuladoras não mostram nenhuma reação ao estresse (no effect level). Por apresentarem recuperação na ecologia do ecossistema são consideradas organismos monitor (biomonitor). São plantas de reação especifica para fatores ambientais. Acumulativo não tem reação.

\section{c) Gossypium hirsutum L.}

Por causa do excesso de sais no solo nas regiões de cultivo do Gossypium hirsutum L. trabalhos são desenvolvidos para testar espécies resistente sendo assim, essa cultura é introduzido no ecossistema degradado podendo ser considerada monitor ativo, pois, embora considerada uma planta tolerante a salinidade trabalhos demonstraram reduções substanciais no crescimento e em sua produção quando exposto a essas condições (PRIMO JUNIOR et al., 2005). Dispõe de um péssimo fisiológico e são estenopotentes por não suportarem condições desfavoráveis e, ou presença de elevadas concentrações de salinidade no ambiente em que elas vivem. Queiroz e Bull (2001), analisando Gossypium hirsutum L. constataram que elevadas concentrações de sódio na solução de solo, prejudicou o crescimento das plantas, a produção de matéria seca e a área foliar.

Pelos motivos citados no parágrafo anterior é notável que a Gossypium hirsutum L. são bioindicadores indireto (secundaria) por serem afetadas pelo manejo inadequado do solo e da água pela ação antrópica. Caracterizando-se como Kestrategista por possui uma maior experiência ambiental, especializadas a respeito de um fator não suportando sua variação. De curto tempo altera seu comportamento e fisiologia conforme acontece o estimulo a resposta é na hora. $\mathrm{Na}$ analise temporal elas reagem com intensidade, durante muito tempo. Considera-se como sentinela ou monitor ativo espécie introduzida no ecossistema. De reação não especifica sofrendo alteração conforme provocada por diferentes fatores ambientais. Sensível por reagir a alterações etiológicas.

\section{CONCLUSÃO}

A espécie Gossypium hirsutum embora caracterizada como boa bioindicadora por causa das suas propriedades ecológicas para solos salinos é uma espécie pouco eficiente por não se adaptar nem recurar esses solos.

Os resultados obtidos demonstraram ainda que a espécie Atriplex nummularia se desenvolve muito bem em solos com elevada concentrações salinas e é usada para extrair os sais desses solos, entretanto, A. nummularia não se comporta como bom bioindicador por não alterar suas características e adaptarse a o ambiente. A espécie Copernicia prunifera é considerada um bioindicador mais promissor de solos salinos, embora sobrevivam a essas condições em concentrações maior ou igual a 100 mol. $\mathrm{m}^{-3}$ de $\mathrm{NaCl}$ o desenvolvimento e possivelmente a vida da planta é comprometida, ou seja, se seu ambiente for modificado essa planta irá alterar suas características identificando a qualidade do ambiente, dessa maneira torna-se a espécie bioindicadora mais ideal.

Os estudos em torno do tema indicam a importância de uma maior atenção por parte da pesquisa científica, necessitando de abordagens investigativas mais frequentes e aprofundadas como estudo laboratorial das espécies a fim de confirmar os dados e para melhor entendimento da complexidade desse processo.

\section{REFERÊNCIAS BIBLIOGRÁFICAS}

ARRUDA, G. M. T.; CALBO, M. E. R. Efeitos da inundação no crescimento, trocas gasosas e porosidade radicular da carnaúba (Copernicia prunifera (Mill.) H.E. Moore). Acta bot. bras. Vol. 18, n.2: Brasília, DF, p. 219-224. 2004, ISSN 0102-3306.

BARROSO, G. M.; GUIMARÃES, E. F.; ICHASO, C. L. F.; COSTA, C. G.; PEIXOTO, A. L. Sistemática das angiospermas do Brasil. Universidade Federal de São Paulo. Livros Técnicos Científicos Editora S.A: Rio de Janeiro, v.1. 245 p.1978a.

BARROSO, G.M.; PEIXOTO, A. L.; COSTA, C. G.; ICHASO, C. L. F.; GUIMARÃES, E. F.; Sistemática de angiospermas do Brasil. Viçosa: Imprensa Universitária UFV, 1986-91. 3v. 377 p. 1991 b.

BERG, E. V. Botânica Econômica. UFLA - Universidade Federal de Lavras. Lavras, MG. 2005. 59p. Disponível em: <http://biologybrasil.blogspot.com/2009/08/botanicaeconomica.html >.Acesso em 23/05/2013.

BONILLA, O. H.; TABOSA, J. N.; GALINDO, F. A. T.; AZEVEDO NETO, A. D. de. Atriplex: nova forrageira para solos salinizados no semi-árido nordestino. Recife: IPA, 2000. 25p.

BRASIL. Ministério do Meio Ambiente. Parentes Silvestres das espécies de plantas cultivadas. Brasília: MMA, 2006. 42 p.

CARVALHO, J. M. F. de.; GOMES, J. M. A. A pobreza nos carnaubais piauienses. VI Encontro da Sociedade Brasileira de Economia Ecológica - ECOECO. Mesa 05: Pobreza e Meio Ambiente. Teresina, 24 p. 2005.

D'ELBOUX, R. M. M. Uma promenade nos trópicos: os barões do café sob as palmeiras-imperiais, entre o Rio de Janeiro e São Paulo, Anais do Museu Paulista, v. 14, n.2, 2006.

EL-DEIR, S. G.; LEITAO, S. N.. Bioindicadores de qualidade ambiental. 1. ed. Recife: Instituto Brasileiro Procidadania, 2009. v. 1. 298p.

FREIRE, M. B. G.; SOUZA, E. R.; FREIRE, F. J. Fitorremediação de solos afetados por sais. In: GHEYI, H. 
R.; DIAS, N. S.; LACERDA, C. F. Manejo da salinidade na agricultura. Fortaleza, INCT Sal, 2010. 472p.

GOMES, R. P. A Germinação da Carnaubeira. Rodriguésia, Rio de Janeiro, v. 10, n. 20, p.1-5 p, 1946.

HOLANDA, S. J. R. Efeito da salinidade induzida no desenvolvimento e crescimento inicial de Carnaúba (Copernicia prunifera(Miller) H.E.Moore): suporte a estratégias de restauração em áreas salinizadas. Universidade Federal Ceará. (Dissertação de Mestrado), Fortaleza, 2006.

HOLANDA, S. J. R.; ARAÚJO, F. S. de., GALLÃO, M. I., FILHO, S. M. Impacto da salinidade no desenvolvimento e crescimento de mudas de carnaúba (Copernicia prunifera (Miller) H.E.Moore). R. Bras. Eng. Agríc. Ambiental [online], v.15, n.1, p.47-52, 2011, ISSN 18071929.

JINDAL, P. C.; SINGH, J. P.; GUPTA, O. P. Studies on salt tolerance in mango-injurious effects of salt on young mango seedlings. Prog. Hort. v. 8, n. 1, p. 65-71, 1976.

JOHNSON, R. K.; WIEDERHOLM, T.; ROSENBERG, D. M.. Freshwater bioimonitoring using in dividual organisms, populations, and species as seblanges of benthic macroinvertebrates. In: ROSENBERG, D. M.; RESH, V. H. (ed.). Freshwater biomoitoring and benthic macroin vertebrates. New York: Chapman \& Hall, 40 - 158 p., 1993.

LAUCHLI, A.; EPSTEIN, E.. Mechanismsof salt tolerance in plants. California Agriculture. p. 18-20, 1984.

LARCHER, W. Ecofisiologia vegetal. São Carlos: RiMa, 2000. $531 \mathrm{p}$.

LEAL, I. G.; ACCIOLY, A. M. de. A.; NASCIMENTO, C. W. A. do.; FREIRE, M. B. G. dos S.; MONTENEGRO, A. A. de A.; FERREIRA, F. de L. Fitorremediação de solo salino sódico por Atriplex nummularia e gesso de jazida. Rev. Bras. Ciênc. Solo. 2008, vol.32, n.3, pp. 1065-1072. ISSN 0100-0683.

MELLO, F. A. F.; BRASIL SOBRINHO, M. O. C.; ARZOLLA, S.; SILVEIRA, R. I.; COBRA NETTO, A.; KIEHL, J. C. Fertilidade do solo. São Paulo, Nobel, 1983. 400 p.

MUNNS, R. Comparative physiology of salt and water stress. Plant, Cell \& Environment, v.25, p.239-250, 2002.

OVERSTREET, C. Reniform nematode-an introduction. In: BELTWIDE COTTON PRODUCTION RESEARCH CONFERENCES, 1999, Orlando. Proceedings... Memphis. Natl. Cotton Counc. Am., 1999, v. 1, p. 42:42.
PORTO, E. R.; AMORIM, M. C. C. de.; DUTRA, M. T.; PAULINO, R. T.; BRITO, L. T. de L.; MATOS, A. N. B.. Rendimento da Atriplex nummularia irrigada com efluentes da criação de tilápia em rejeito da dessalinização de água. Rev. bras. eng. agríc. ambient. 2006, vol.10, n.1, pp. 97-103. ISSN 1807-1929.

PRIMO JUNIOR, J. R.; LOPES, J. DA S.; MACHADO, M DOS S.; PEIXOTO, C. P.; SILVA, S. A. Efeitos da salinidade na germinação de sementes e crescimento de plântulas de algodão (Gossypium hirsutumL). In: CONGRESSO BRASILEIRO DE ALGODÃO, 5, 2005, Salvador. Algodão: uma fibra natural: Resumos. Salvador: ABAP A, 2005.

QUEIROZ, S. O. P. de.; BÜLL, L. T. Comportamento de genótipos de algodão herbáceo em função da salinidade do solo, 2001. Revista Irriga,v. 6, n. 2, p. 124-134, 2001.

ROCHA, T. G. F.; SILVA, R. A. R.; MARINHO, A. de A.; FAJARDO, C. G.; VIEIRA, F. de A. Demografia da palmeira Copernicia prunifera (MILL) H. E. MOORE: Analise temporal do padrão espacial. in $\mathbf{X}$ Congresso de Ecologia do Brasil, 16 - 22 de Setembro de 2011, São Lourenço - MG, 2p.

TAKHTAJAN, A. Outline of the classification of flowering plants (Magnoliophyta). Bot. Rev., Bronx, v. 46, n. 3, p. 225-359, 1980.

TAIZ L.; ZEIGER, E. Fisiologia vegetal. 3 ed. Porto Alegre:Artmed, 2004. 719p.

TOPPA, E. V. B.; BRAMBILLA, W. P. O melhoramento de plantas e a salinidade dos solos. Revista Verde. Mossoró, RN, v.6, n.1, p. 21-25. 2011. ISSN 1981-8203.

ZID, E. Influence du Chlorure de Sopdium sur la Croissance et la Nutrition Minerale d'Atriplex halimus var. halimus. Tunis, Tunísia: Centre de Recherche du Problem Zone Aride. 1970. 